\title{
NUMERICAL SIMULATIONS OF HYDRODYNAMIC OPEN-WATER CHARACTERISTICS OF A SHIP PROPELLER
}

\author{
Judyta Felicjancik \\ CTO S.A. Ship Design and Research Centre, Gdansk \\ Environmental Doctoral Studies at Gdansk University of Technology, Faculty of Mechanical Engineering \\ Sebastian Kowalczyk \\ CTO S.A. Ship Design and Research Centre, Gdansk \\ Karol Felicjancik \\ Krzysztof Kawecki \\ Bota Technik Sp. z o.o. Limited Partnership
}

\begin{abstract}
The paper presents the results of numerical simulations of ship propeller operation bearing the name of Propeller Open Water (POW) Tests. The object of tests was a sample ship propeller (PPTC1), the geometrical and kinematic data of which are available, along with the results of model tests, on the official page of the research centre involved in the measurements. The research aimed at verifying the correctness of results of numerical simulations performed in the model and real scale. The results of numerical analyses performed in the model scale were confronted with those measured in the experiment. Then, making use of dimensionless coefficients which characterise propeller's operation, the recorded model data were extrapolated to real conditions and compared with corresponding results of simulations. Both the numerical simulations and the experimental research were performed for the same propeller load states. The reported research is in line with other activities which aim at developing advanced numerical methods to support the process of ship propeller designing. .
\end{abstract}

1 Potsdam Propeller Test Case: http://www.sva-potsdam.de/pptc-smp11-workshop/

Keywords: CFD, model tests, POW Test, propeller, validation

\section{INTRODUCTION}

Intensive development of computational fluid dynamics (CFD) methods allows nowadays to model the operation of a ship propeller in homogeneous velocity field in order to determine its hydrodynamic characteristics (similar to so-called propeller open water tests performed experimentally). The hydrodynamic open-water characteristics of a ship propeller have the form of dimensionless thrust coefficient $K_{T}$ and torque coefficient $K_{Q}$ as functions of the advance coefficient J for constant pitch ratio $P / D$. Determining ship propulsion characteristics, i.e. diagrams of propeller thrust, torque, and power as ship speed functions for constant propeller revolutions is essential for determining the propeller operation point. Selecting an optimal advance speed for the given power passed to the propeller at its nominal revolutions results in more efficient fuel consumption. The hydrodynamic characteristics, applicable in propeller designing, are obtained from model tests which precisely maintain geometric similarity of the model and real propeller, as well as the similarity of water flow in the vicinity of the model and real propeller (referred to as kinematic similarity). These tests can have the form of open water propeller model tests or self-propelled ship model tests.

The use of advanced numerical methods, verified on the results of model tests, is a significant step towards full modelling of phenomena which accompany ship propeller operation in real conditions. It is noteworthy, however, that attempts to improve the level of accuracy of the performed 
numerical simulations, for instance by modelling real and not simplified geometry of the propeller, or taking into account real cavitation phenomena, should always be followed by experimental verification of the obtained results.

The experimental results which are most frequently used to validate numerical methods are usually obtained from in-house tests, or those performed by other research centres and made available for international comparison tests. Based on the results of the in-house tests, a methodology of numerical analyses has been developed in the Ship Design and Research Centre (CTO SA) which allows to assess and predict cavitation on a ship propeller [12]. The developed methodology was verified on the results of cavitation which was experimentally measured on the propeller CP4691 in the CTO SA cavitation tunnel. The results of verification were presented at the international conference on advanced measurement techniques in Istanbul, Turkey [7]. The results of cavitation observation were complemented by analyses of hydroacoustic effects accompanying the modelled phenomenon. Finally, the results of numerical analyses and experimental measurements were compared. The result of the performed comparison was satisfying.

International comparison tests make it possible to compare results of in-house examination with those obtained in other research centres using different simulation codes and methodologies. This way was used to verify a valuable numerical method for ship propulsion analyses which was developed in CTO $[3,5]$. The company Bota Technik sees considerable benefits coming from the use of this method, which manifest themselves, among other aspects, in increased efficiency and reliability of the ship propulsion design process. This method can be widely implemented and practically used by Bota Technik in realisation of design tasks, as well as in research and development activities.

The propeller used as the object of numerical and model examination has been designed to meet the needs of an international comparison test (benchmark test) and does not exist in real scale. The hydrodynamic characteristics of the sample propeller were generated as a result of standard tests performed in the model basin to validate numerical methods. The here examined propeller was designed in such a way as to allow the open water propeller to be tested within a wide velocity range of parameters of the approaching flow, including developed cavitation conditions. The experimental measurements were performed in the model basin and in the cavitation tunnel owned by the SVA Centre, Potsdam, Germany $[2,15]$.

In that experiment the propeller was tested in conditions corresponding to the tow test, with shaft immersion equal to 1.5 of propeller diameter $\mathrm{D}$. In the resent research, to obtain open water propeller characteristics the simulation calculations were performed for the following values of the advance coefficient $J: 0.6,0.8,1.0,1.2$ and 1.4. The range of analysis usually includes the design operation point, i.e. the parameter for which the propeller has been designed. In the

1 Ship propeller CP469 is a four-blade adjustable pitch propeller of the Polish training and research vessel „Nawigator XXI”. paper, the results of experimental and numerical examination of the propeller are shown in the form of dimensionless thrust and torque coefficients as functions of rotational speed $\mathrm{n}$ and diameter $\mathrm{D}$ of the propeller, and water density $\rho$ (1-4) [6]:

The propeller thrust coefficient:

$$
K_{T}=\frac{T}{\rho n^{2} D^{4}}
$$

The propeller torque coefficient:

$$
K_{Q}=\frac{Q}{\rho n^{2} D^{5}}
$$

Speed (advance) coefficient:

$$
J=\frac{V_{A}}{n D}
$$

Propeller efficiency:

$$
\eta_{0}=\frac{J}{2 \pi} \frac{K_{T}}{K_{Q}}
$$

where: $T$ - thrust [N]; $Q$ - torque $[\mathrm{Nm}] ; V_{A}$ - advance speed $\left[\mathrm{m} \mathrm{s}^{-1}\right]$

\section{DESCRIPTION OF THE EXAMINED OBJECT}

The object of the analysis was a five-blade propeller identified as VP1304 (or PPTC), with the designed pitch coefficient $P_{0.7} / D=1.635$. This is a right-handed adjustable pitch propeller with the diameter $\mathrm{D}=0.25 \mathrm{~m}$ in the model scale. The adjustment system affects the structure of propeller blades near the hub (a gap of $0.3 \mathrm{~mm}$ in width between the hub and the blade root), as well as the leading and trailing edges $[1,11]$. The propeller geometry is schematically shown in Fig. 2. Geometric data of the propeller for real conditions were obtained by proper scaling. Moreover, the forecast of propeller operation in real conditions, used for comparison with the results of numerical calculations, was obtained as extrapolation of the model data. Such forecasting is a standard procedure, which bases on available results of model tests. The propeller diameter in the real scale, calculated using the scale coefficient, was equal to $3 \mathrm{~m}$. Water parameters (density, viscosity) corresponded to real values, characteristic for given basin conditions. Basic geometric data of the propeller are collated in Table 1.

Table 1. Basic data of propeller VP1304

\begin{tabular}{|l|c|c|c|c|}
\hline & Symbol & Unit & Real scale & Model scale \\
\hline $\begin{array}{l}\text { No. of propeller } \\
\text { model }\end{array}$ & - & - & & VP1304 \\
Type of propeller & - & - & \multicolumn{2}{|c|}{ CPP } \\
Diameter & $\mathrm{D}$ & $\mathrm{m}$ & 3 & 0.25 \\
$\begin{array}{l}\text { Design pitch } \\
\text { coefficient for } \\
r / R=0.7\end{array}$ & P0.7/D & - & \multicolumn{2}{|c|}{1.635} \\
$\begin{array}{l}\text { Expanded blade } \\
\text { area ratio }\end{array}$ & AE /A0 & - & \multicolumn{2}{|c|}{0.779} \\
\hline
\end{tabular}




\begin{tabular}{|l|c|c|c|c|}
\hline & Symbol & Unit & Real scale & Model scale \\
\hline Hub coefficient & $d h / D$ & - & \multicolumn{2}{|c|}{0.300} \\
Number of blades & $Z$ & - & \multicolumn{2}{|c|}{5} \\
$\begin{array}{l}\text { Direction of } \\
\text { rotation }\end{array}$ & & - & \multicolumn{2}{|c|}{ Right-handed } \\
Scale coefficient & $\lambda$ & - & 1 & 12 \\
\hline
\end{tabular}

\section{BOUNDARY CONDITIONS AND} CALCULATION METHOD

The calculations which made the basis for hydrodynamic characteristics of the examined propeller in model and real scale were performed using the code STAR CCM+. The flow past the propeller was modelled using the unsteady flow model based on the Reynolds-Averaged Navier-Stokes (RANS) equations and the two-equation "SST k-omega" turbulence model. Flow modelling with the aid of RANS equations enables to obtain reliable results, at the same time preserving acceptable calculation times, due to the use of a simpler equation to close the basic system of Navier-Stokes equations. The applied turbulence model, recommended for the here examined type of flow, links together main advantages of basic $\mathrm{k}-\varepsilon$ and $\mathrm{k}-\omega$ models, and introduces a term which limits overproduction of kinetic energy of turbulence in the areas with high pressure gradients. The $\mathrm{k}-\varepsilon$ model well models the turbulence in the free flow area and reveals low susceptibility of quantities describing the turbulence to inlet conditions. In turn, the k- $\omega$ model much better models the flow in the boundary layer, but is very susceptible to free-stream turbulence values. The applied combined model, transformed from the $\mathrm{k}-\varepsilon$ form to the equations for $\mathrm{k}$ and $\omega$, was complemented by introducing a SST (Shear Stress Transport) term which limits principal stresses in the flow [13].

The flow past the propeller VP1304 was modelled in a cylindrical domain having the following dimensions, expressed as multiples of propeller diameter D: 5D forward, 10D rearward, and 10D in diameter, see Fig.1. A homogeneous flow field was assumed at inlet. Table 2 collates basic data adopted as conditions for calculations in the both scales. The model scale reflects conditions of model propeller operation in the model basin, while the full scale corresponds to standard sea conditions. In both cases the calculation time step was assumed in such a way that it corresponded to the same fraction of full propeller revolution in both scales.

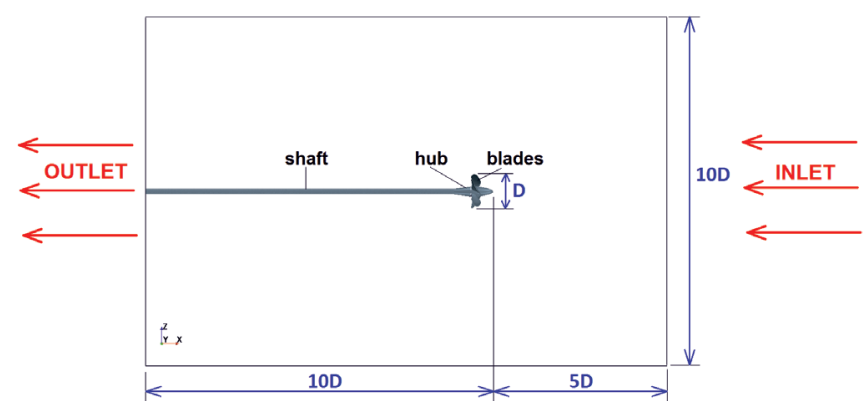

Fig. 1. Computational domain of the propeller VP1304
Table 2. Basic data assumed in calculations

\begin{tabular}{|c|c|c|c|}
\hline & & \multicolumn{2}{|c|}{ VP1304 } \\
Parameter & Unit & Model scale & Real scale \\
\hline Water density & $\mathrm{kg} \mathrm{m}^{-3}$ & 999.00 & 1025.87 \\
Kinematic viscosity of water & $\mathrm{m}^{2} \mathrm{~s}^{-1}$ & $1.139 \mathrm{E}-6$ & $1.188 \mathrm{E}-6$ \\
$\begin{array}{c}\text { Propeller revolutions } \\
\text { Propeller revolution per time } \\
\text { step }\end{array}$ & $\mathrm{s}$ & 15.00 & 4.33 \\
\hline \multicolumn{2}{c|}{} & 3 & 3 \\
\hline
\end{tabular}

The computational domain was discretised using the finite volume method (FVM), which consists in dividing the computational domain into a finite number of small elements bearing the name of control volumes and integrating the conservation equations over these elements. The method adapts to each type of grid and therefore is well applicable to the complex geometry of the examined propeller. The shape of the control volume can be arbitrary, which is a reason why this method is so popular and frequently used to solve fluid mechanics equations [8].

The calculations were performed on an unstructured polyhedral grid with the boundary layer surrounding the entire propeller (Fig. 2). Cell dimensions were adapted locally, based on the resultant values of Y+, a parameter defining the way in which the equations are solved within the boundary layer [14]. As a result of domain discretisation, the grid consisting of over 5.5 million of finite volumes was obtained. Proper grid refinement on the propeller surface was needed to model properly the complicated geometry of propeller blades with sharp leading and trailing edges. Additional grid refinement in other space sections provided opportunities for better flow modelling near the propeller [4].

The calculation grid for the real scale cannot be generated via direct multiplication of node coordinates from the model scale by the scale coefficient. In general, surface elements on the outer walls of the propeller and volumetric elements of the major part of the computational domain can be scaled in this way, but direct scaling of dimensions of the cells composing the boundary layer is incorrect. The relative thickness of the boundary layer decreases with the increasing Reynolds number, i.e. is smaller for the real scale. Moreover, the boundary layer is related with the turbulence scales, which also change in proportion to the changing dimensions of the object. Proper modelling of flow phenomena requires adapting grid elements in the boundary layer to the nature of the flow, which in practice means decreasing the relative thickness of elements in the direction normal to the object's walls. The phenomena taking place in the boundary layer heavily affect the hydrodynamic drag of objects moving in the fluid, therefore their proper modelling is of primary importance for the performed analyses.

The propeller revolution was modelled using the model with steady reference frame (SRF), which simulated real propeller revolution in the domain, taking into account the grid motion. The water flow was in the direction of the $\mathrm{X}$-axis. 

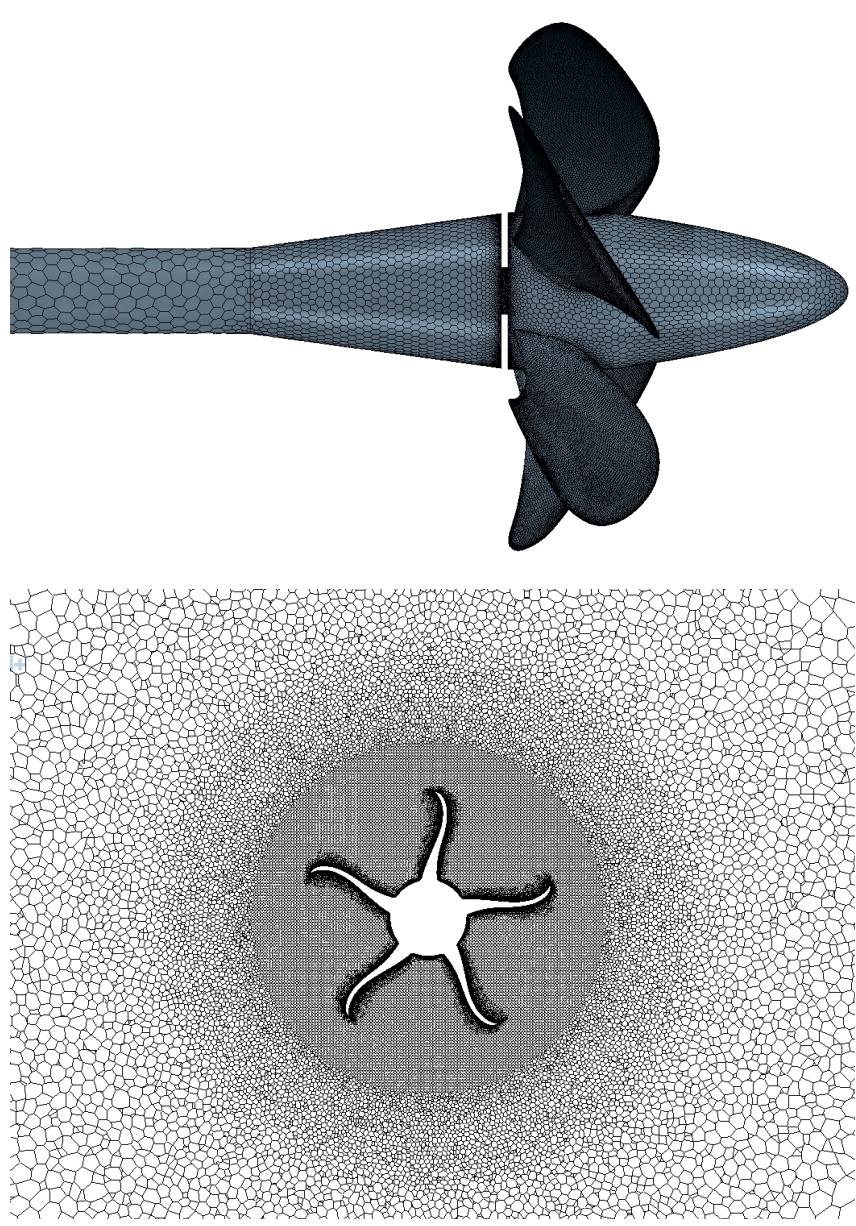

Fig. 2. Grid visualisation: a) on propeller, b) in propeller circle cross-section

\section{RESULTS AD DISCUSSION}

The results of the numerical analyses, performed within a wide range of parameters, are collated in Tables 3-11, while the open water propeller characteristics are shown in diagrams in Fig. 3-5. Thrusts and torques were calculated only for propeller blades, and read after the forces have reached a proper convergence level. In each case (calculation point) the computing time was not the same.

Tables 3-5 collate numerical results (labelled as CFD) obtained from propeller calculations performed in the model scale. These results are compared with widely available experimental results (labelled as EFD) of examination of the same sample propeller. When the propeller load decreases (with the resultant increase of the advance coefficient $J$ ), the difference between calculations and experiment increases, both for the thrust coefficient $K_{T}$ and the torque coefficient $10 \mathrm{KQ}$. As a consequence, the difference between the values of propeller efficiency $\eta O$ calculated and measured for the same load also increases. In Fig. 3 we can clearly see underestimation of operating parameters of the propeller for lower loads, for which the obtained coefficient values are becoming smaller. This is reflected in efficiency changes, as it depends on the both coefficients. The obtained values can also be affected by the quality do the modelled geometry. The numerical analyses were performed using the available geometry with sharp trailing edges, which in fact, for technological reasons, have limited radiuses in the real propeller version used in model tests.

\begin{tabular}{|c|c|c|c|}
\multicolumn{4}{c|}{ Table 3. Experimental results for model scale } \\
\hline$J$ & \multicolumn{3}{|c|}{$\begin{array}{c}\text { EFD } \\
\text { model scale }\end{array}$} \\
\hline 0.6 & $K_{T, E F D}$ & $10 K_{Q, E F D}$ & $\eta_{O, E F D}$ \\
0.8 & 0.629 & 1.396 & 0.430 \\
1.0 & 0.510 & 1.178 & 0.551 \\
1.2 & 0.399 & 0.975 & 0.652 \\
1.4 & 0.295 & 0.776 & 0.726 \\
\hline
\end{tabular}

\begin{tabular}{|c|c|c|c|}
\multicolumn{4}{|c|}{ Table 4. Numerical results for model scale } \\
\hline$J$ & $K_{T, C F D}$ & $\begin{array}{c}\text { CFD } \\
\text { model scale }\end{array}$ \\
\hline 0.6 & 0.622 & $10 K_{Q, C F D}$ & $\eta_{O, C F D}$ \\
0.8 & 0.496 & 1.422 & 0.417 \\
1.0 & 0.375 & 1.187 & 0.532 \\
1.2 & 0.263 & 0.961 & 0.621 \\
1.4 & 0.152 & 0.742 & 0.677 \\
\hline
\end{tabular}

Table 5. Comparing experimental and numerical results for model scale

\begin{tabular}{|c|c|c|c|}
\hline \multirow{2}{*}{$J$} & \multicolumn{3}{|c|}{$\begin{array}{c}\text { Difference } \\
\text { (EFD mod-CFD mod) }\end{array}$} \\
\cline { 2 - 4 } & $\Delta K_{T}$ & $\Delta 10 K_{Q}$ & $\Delta \eta_{O}$ \\
\hline 0.6 & 0.007 & -0.026 & 0.013 \\
\hline 0.8 & 0.014 & -0.009 & 0.019 \\
\hline 1.0 & 0.024 & 0.014 & 0.031 \\
\hline 1.2 & 0.032 & 0.034 & 0.049 \\
\hline 1.4 & 0.036 & 0.050 & 0.084 \\
\hline
\end{tabular}

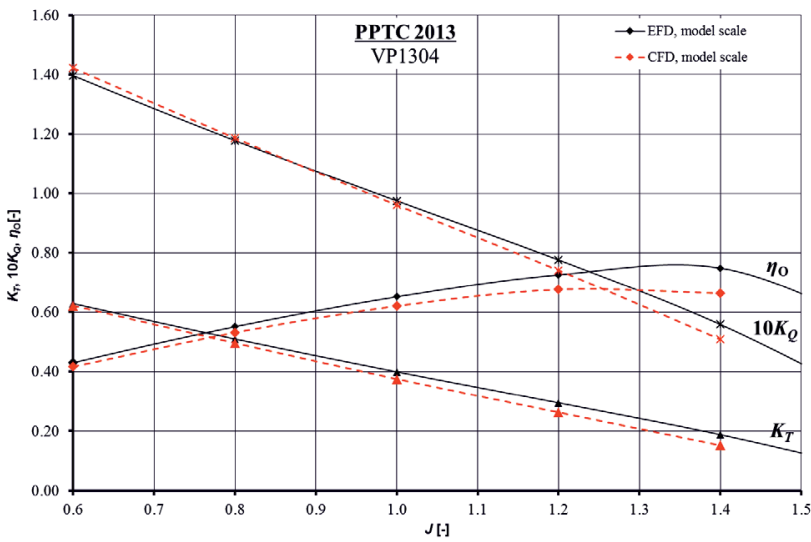

Fig. 3. Comparing experimental data and numerical results for model scale

Tables 6-8 collate numerical results (marked $C_{F D S}$ ) obtained from propeller calculations performed in the real scale. These results are compared with widely available experimental 
results (marked $E F D_{S}$ ) of examination of the same sample propeller.

For lower propeller loads, mainly corresponding to the advance coefficient values $J>0.8$, the difference between the calculated and measured values of the thrust coefficient $K_{T}$ increases. Moreover, the calculated values move from the area of slight overestimation to the area of underestimated values. Nevertheless, the shape of the curve is very close to that expected within the analysed operation range. The curve of the torque coefficient $10 \mathrm{~K}_{Q}$ is more inclined, as compared to the reference curve. The advance coefficient $J=1.05$ is the point of intersection of the both curves. From this point on, the numerical values are underestimated for lower propeller loads $(J>1.05)$ and overestimated for higher loads $(J<1.05)$. The values of propeller efficiency $\eta_{O}$ are underestimated within the entire operating range, and the difference between the results of measurement and calculations increase with the decreasing load. In Fig. 4 the abovementioned relations between the numerical and experimental results are clearly visible.

Table 6. Experimental results for real scale

\begin{tabular}{|c|c|c|c|}
\hline \multirow{2}{*}{$J$} & \multicolumn{3}{|c|}{$\begin{array}{c}\text { EFDS } \\
\text { real scale }\end{array}$} \\
\hline & $K T, E F D S$ & $10 K_{Q, E F D S}$ & $\eta_{O, E F D S}$ \\
\hline 0.6 & 0.631 & 1.386 & 0.435 \\
\hline 0.8 & 0.512 & 1.168 & 0.558 \\
\hline 1.0 & 0.401 & 0.965 & 0.662 \\
\hline 1.2 & 0.297 & 0.766 & 0.740 \\
\hline 1.4 & 0.190 & 0.549 & 0.770 \\
\hline
\end{tabular}

Table 7. Numerical results for real scale

\begin{tabular}{|c|c|c|c|}
\hline \multirow{2}{*}{$J$} & \multicolumn{3}{|c|}{$\begin{array}{l}\text { CFDS } \\
\text { real scale }\end{array}$} \\
\hline & $K T, C F D S$ & $10 K Q, C F D S$ & $\eta O, C F D S$ \\
\hline 0.6 & 0.636 & 1.430 & 0.424 \\
\hline 0.8 & 0.511 & 1.196 & 0.544 \\
\hline 1.0 & 0.390 & 0.970 & 0.640 \\
\hline 1.2 & 0.280 & 0.753 & 0.709 \\
\hline 1.4 & 0.170 & 0.522 & 0.726 \\
\hline
\end{tabular}

Table 8. Comparing experimental and numerical results for real scale

\begin{tabular}{|c|c|c|c|}
\hline \multirow{2}{*}{$\mathrm{J}$} & \multicolumn{3}{|c|}{ Difference } \\
& $\Delta K_{T}$ & $\Delta 10 K_{Q}$ & $\Delta \eta_{O}$ \\
\hline 0.6 & 0.005 & 0.044 & -0.011 \\
0.8 & 0.001 & 0.028 & -0.014 \\
1.0 & -0.011 & 0.005 & -0.022 \\
1.2 & -0.017 & -0.013 & -0.031 \\
1.4 & -0.020 & -0.027 & -0.044 \\
\hline
\end{tabular}

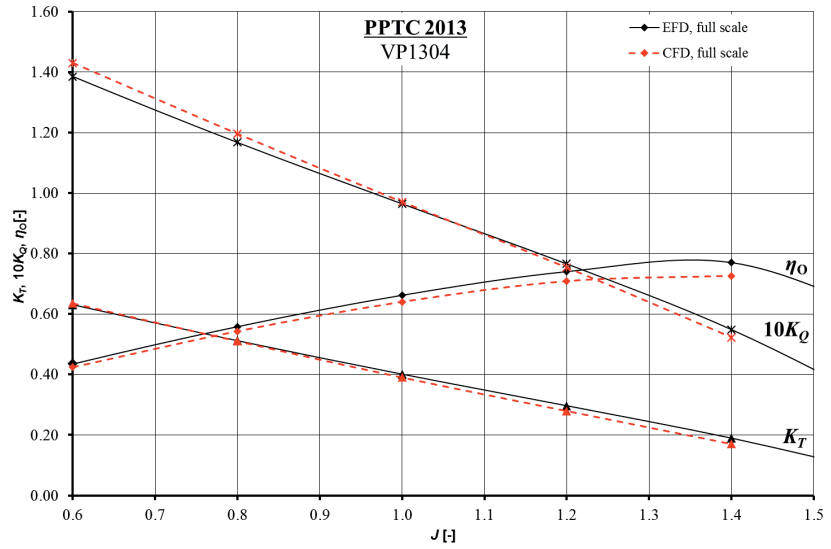

Fig. 4. Comparing experimental data and numerical results for real scale

Tables 9-11 collate differences between numerical and experimental results for the model and real scale. In experimental conditions, the difference is kept at a constant level for both the trust coefficient $K_{T}$ and the torque coefficient $10 K_{Q}$, which results from the fact that the results for the real scale were obtained from extrapolation of the model results. However, the propeller efficiency difference $\Delta \eta \mathrm{O}$ increases with the decreasing propeller load. As for the numerical results, the differences between them are not kept precisely at the same level, but take similar values for both the thrust coefficient $\mathrm{KT}$ and the torque coefficient $10 K_{0}$. The propeller efficiency difference $\Delta \eta_{O}$ increases with the decreasing propeller load. It can be seen in Fig. 5 that despite similar trends in coefficient differences in both cases, the efficiency difference for the numerical case significantly increases with the increasing advance coefficient. This tendency is likely to be related with the scaling effect, as the extrapolation of model basin results $\left(K_{T}\right.$ and $\left.10 K_{Q}\right)$ is clearly kept at a constant level, while the efficiency $\eta_{O}$ calculated from these quantities reveals a similar trend to that of the numerically obtained difference curve.

Table 9. Comparing experimental results for model and real scale

\begin{tabular}{|c|c|c|c|}
\hline \multirow{2}{*}{$\mathrm{J}$} & \multicolumn{3}{|c|}{ Difference } \\
& $\Delta K_{T}$ & $\Delta 10 K_{Q}$ & $\Delta \eta_{O}$ \\
\hline 0.6 & 0.002 & -0.010 & 0.005 \\
0.8 & 0.002 & -0.010 & 0.007 \\
1.0 & 0.002 & -0.010 & 0.010 \\
1.2 & 0.002 & -0.010 & 0.014 \\
1.4 & 0.002 & -0.010 & 0.021 \\
\hline
\end{tabular}

Table 10. Comparing numerical results for model and real scale

\begin{tabular}{|c|c|c|c|}
\hline \multirow{2}{*}{$J$} & \multicolumn{3}{|c|}{ Difference } \\
& $\Delta K_{T}$ & $\Delta 10 K_{Q}$ & $\Delta \eta_{O}$ \\
\hline 0.6 & 0.014 & 0.009 & 0.007 \\
0.8 & 0.015 & 0.009 & 0.011 \\
1.0 & 0.015 & 0.010 & 0.019 \\
\hline
\end{tabular}




\begin{tabular}{|c|c|c|c|}
\hline \multirow{2}{*}{$J$} & \multicolumn{3}{|c|}{ Difference } \\
& $\Delta K_{T}$ & $\Delta 10 K_{Q}$ & $\Delta \eta_{O}$ \\
\hline 1.2 & 0.017 & 0.012 & 0.032 \\
1.4 & 0.019 & 0.014 & 0.062 \\
\hline
\end{tabular}

Table 11. Comparing differences between numerical and experimental results for model and real scale

\begin{tabular}{|c|c|c|c|}
\hline$J$ & \multicolumn{3}{|c|}{$\begin{array}{c}\text { Difference } \\
\text { (EFD - CFD) }\end{array}$} \\
& $\Delta K_{T}$ & $\Delta 10 K_{Q}$ & $\Delta \eta_{O}$ \\
\hline 0.6 & -0.012 & 0.001 & -0.002 \\
0.8 & -0.013 & 0.001 & -0.004 \\
1.0 & -0.013 & -0.020 & -0.009 \\
1.2 & -0.015 & -0.022 & -0.018 \\
1.4 & -0.017 & -0.024 & -0.041 \\
\hline
\end{tabular}

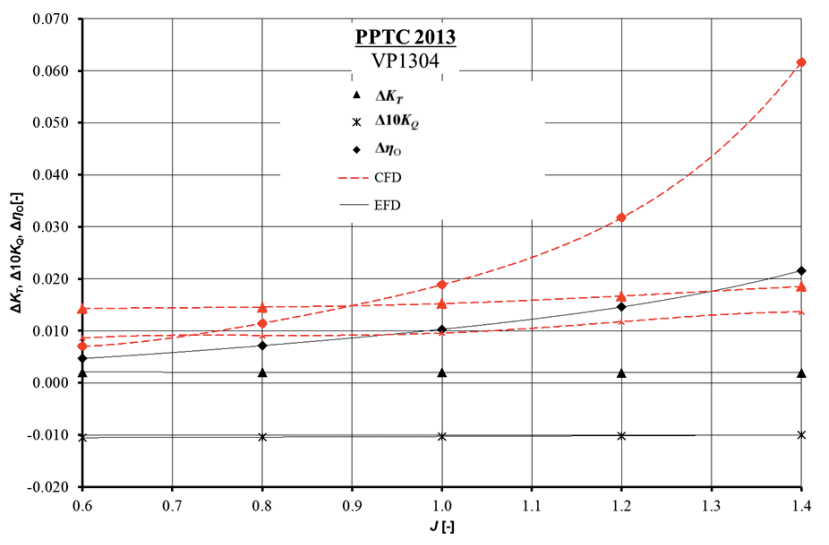

Fig. 5. Comparing differences between numerical and experimental results for model and real scale

\section{CONCLUSIONS}

The results of numerical simulations of open water propeller operation, performed within the framework of international comparison workshops, enabled to verify the applied methods by comparing with the experimentally measured results. Public availability of the data on propeller geometry and its experimental examination provides opportunities for wide validation of numerical methods and comparing the quality of in-house achievements with the results obtained in other research centres. The results of numerical simulations performed in CTO SA reveal similar trends in the shapes of hydrodynamic characteristics of the examined propeller within the entire range of the advance coefficient. The differences between CFD and EFD results are small for higher values of the advance coefficient $J$. The highest discrepancy is observed in propeller efficiency results obtained for highest advance coefficient in the real scale. Although the general trend of the analysed differences is similar, the exact values differ much between each other. It is noteworthy, however, that the values for the real scale were obtained from extrapolation of the results of model tests and not from measurements, which raises the question whether the observed differences reflect real nature of the simulated phenomena or are a consequence of the adopted extrapolation method.

The methodology of numerical simulations which was applied in CTO SA allows to obtain results, the quality of which is similar to those presented by other major research centres $[9,10,11]$. The developed method is similar to those quoted in the references and models the nature of the examined phenomena with the accuracy which is sufficiently high to recommend it for practical use.

Due to high convergence of the performed analyses, and the resultant high credibility of the obtained results, the use of the presented method by the design office of Bota Technik will considerably enhance their capacity in selection and design of ship propellers. The company Bota Technik will be able to offer the ship owner a properly selected propeller with its full characteristics. This ability will make a clear added value for the ship owner, and will allow the company to strengthen its competitiveness on the demanding market of ship propellers.

\section{BIBLIOGRAPHY}

1. Barkmann U.: Potsdam Propeller Test Case (PPTC) - Open Water Tests with the Model Propeller VP1304. Report 3752, Schiffbau-Versuchsanstalt Potsdam, Germany 2011.

2. Barkmann U., Heinke H.J., Lubke L.: Potsdam Propeller Test Case (PPTC) -Test Case Description. Second International Symposium on Marine Propulsors, SMP'11, Workshop: Propeller performance, Hamburg, Germany 2011.

3. Bugalski T., Hoffmann P.: Numerical simulation of the interaction between ship hull and rotating propeller. Proceedings of a Workshop on Numerical Ship Hydrodynamics, Gothenburg 2010, pp. 441-446.

4. Bugalski T., Hoffmann P.: Numerical simulation of the selfpropulsion model test. Second International Symposium on Marine Propulsors SMP'11, Hamburg, Germany 2011.

5. Bugalski T., Wawrzusiszyn M., Hoffmann P.: Numerical Simulations of the KCS - Resistance and Self-Propulsion. Proceedings of A Workshop on CFD in Ship Hydrodynamics, Vol. III, pp. 251-256, December 2-4, NMRI, Tokyo 2015.

6. Carlton J.: Marine Propellers and Propulsion, Elsevier, Amsterdam-Tokyo 2007.

7. Felicjancik J.: Propeller investigations by means of numerical simulation. The 4th International Conference on Advanced Model Measurement Technology for the Maritime Industry AMT'15, September 28-30, Istanbul, Turkey 2015.

8. Ferziger J.H., Perić M.: Computational Methods for Fluid 
9. Fujiyama K., Ho Kim Ch., Hitomi D.: Performance and Cavitation Evaluation of Marine Propeller using Numerical Simulations. Second International Symposium on Marine Propulsors, SMP'11, Hamburg, Germany 2011.

10. Gornicz T., Kulczyk J.: The Assessment of the Application of the CFD Package OpenFOAM to Simulating Flow around the Propeller. Marine Navigation and Safety of Sea Transportation: Maritime Transport \& Shipping, 247, Poland 2007.

11. Klasson O.K., Huuva T.: Potsdam Propeller Test Case (PPTC). Second International Symposium on Marine Propulsors, SMP'11, Hamburg, Germany 2011.

12. Kowalczyk S., Felicjancik J.: Numerical and experimental propeller noise investigations. Ocean Engineering published by Elsevier (2016), vol. 120, pp. 108-115.

13. Menter F. R.: Two-Equation Eddy-Viscosity Turbulence Models for Engineering Applications. AIAA Journal (1994), Vol. 32, No 8, pp. 1598-1605.

14. Versteeg H.K., Malalasekera W.: An Introduction to Computational Fluid Dynamics the Finite Volume Method. Harlow, England 2007.

15. http://www.sva-potsdam.de/pptc_ittc_switch.html

\author{
Judyta Felicjancik \\ e-mail: judyta.felicjancik@cto.gda.pl \\ Centrum Techniki Okrętowej S.A. \\ Ship Design and Research Center \\ Szczecińska 65 St. \\ 80-392 Gdańsk
}

Poland 